\title{
THE DIFFERENCES BETWEEN TRADITIONAL AND DYNAMIC ASSESSMENT IN DIAGNOSING STUDENTS WITH READING DISABILITIES AT PRIMARY SCHOOL IN THE KINGDOM OF BAHRAIN
}

\author{
Danha Al Hajeri, Nadia Tazi and Mansoor A. Sayyah \\ Arabian Gulf University, Bahrain
}

\begin{abstract}
The study aimed to determine the differences between the traditional and dynamic assessment in the diagnosis of learning disabilities reading among primary school students in Bahrain. The researcher used the descriptive approach, where the number of the sample (48) students. Information of the study was collected using: a word test and a reading comprehension test. The study results showed no statistically significant differences between the numbers of people diagnosed with reading difficulties depending on the kind of assessment (traditional/ dynamic) in favor of the dynamic assessment. The results also showed a statistically significant differences between the numbers of people diagnosed with difficulties in knowing words depending on the kind of assessment (traditional/ dynamic) in favor of the dynamic assessment. The results also showed no statistically significant differences between the number of people diagnosed with difficulties Reading Comprehension depending on the kind of assessment (traditional/ dynamic) in favor of the dynamic assessment.
\end{abstract}

Keywords: Traditional Assessment,Dynamic Assessment,Learning Disabilities, Word Recognition Disability

\section{Introduction}

Educational measurement and evaluation field is considered of one of the main fields in psychology and special education; it includes a set of procedures that aim to get useful, accurate and truthful information about the student (Raussan, 1999).

Perhaps one of the most fundamental issues and problems facing learning disabilities is the ambiguity of the concept of evaluation, as identifying and diagnosing procedures for learning disabilities often lack to the precision and sophistication, so it is difficult to judge that those pupils suffer from learning disabilities depending on some of the properties (Shalaby, 2007).

So a novelty trend has emerged in evaluation, namely the dynamic assessment, and was adopted by many educational programs and proved the effectiveness and impact of the program depending on it, more than the traditional assessment (Melhem, 2012).

Dynamic assessment focuses on the student development and his performance through the adoption of the pretest and posttest model, and teaching the pupils between them and noting the progress made in mental and behavioral performance evolution, and so it is the best and most successful way to detect undiscovered aspects of the pupils (Alharoub, 2012). 


\section{Research Problem}

The educational evaluation process for students with learning disabilities is a systematic process to gather relevant educational information about this disability, in order to take legal and educational decisions when providing special services (Afif, 2014).

The traditional assessment focuses on determining the pupil's current level in comparison to his peers, this may reflect the pupil's various educational experiences, or a lack of educational opportunities, but does not necessarily reflects the real level of the pupil (Al-Sheikh, 2004). So the dynamic assessment supporters think that there is a need to reconsider the traditional assessment that is currently used in tests, and the most important conditions of which are determining the current performance accurately, and remain neutral in interaction and objectivity when conducting tests, and judging the students' level through differentiation degree with a standard set of peers (AL-Sheikh, 2004).

And Through literature review, we can find that some studies have pointed to the success of such dynamic assessment (Swanson, 1994; Al-Sheikh, 2004; Swanson \& Haward, 2005; Salas, Gonzalez \& Assael, 2012).

In light of what mentioned above, on the one hand, and the lack of Arabic studies on dynamic assessment on the other hand, the researcher aims to examine the differences between the traditional assessment and the dynamic assessment in the diagnosis of reading disabilities among primary school pupils in Kingdom of Bahrain.

\section{Research Questions:}

1. Is the number of students diagnosed with reading disabilities differs depending on the assessment type (traditional / dynamic)?

2. Is the number of students diagnosed with reading disabilities in the word recognition skill, differs according to the assessment type (traditional / dynamic)?

3. Is the number of students diagnosed with reading disabilities, in the skill of Reading Comprehension, differs according to the assessment type (traditional / dynamic)?

\section{Research objectives:}

1. To highlight the dynamic assessment a modern trend in the field of evaluation, from which the number of students diagnosed with reading disabilities can be reduced.

2. Identify the differences between the traditional and the dynamic assessment in the diagnosis of reading disabilities among primary school students in the Kingdom of Bahrain.

3. Finding a new assessment method that is based on an attempt to reach into the pupil's Zone of Proximal Development.

\section{The ResearchSignificance}

1. Studying the dynamic assessment as a modern way of evaluation, to replenish the Arabic literature in this aspect.

2. Identifying the steps of building dynamic assessment can help the researchers in this field.

3. Studying the difference between the traditional and the dynamic assessment in the diagnosis of reading disabilities among the primary school pupils could lead to further studies to address the dynamic assessment in other skills, such as writing and arithmetic or with other groups of people with special needs. 
4. The application of dynamic assessment may help in proper diagnosis for people with reading disabilities, and the exclusion of other groups from entering into with learning disabilities.

\section{Research Limitations}

- Spatial limitations: The tools of the current research have been applied in the following schools: Andalus Primary School for Girls, Fatima Bint Al- Khattab Primary School for Girls, Khansa Primary School for Girls, Khalid Bin Al Waleed Primary School for Girls in the cities of Riffa and Isa Town in the Central Governorate in Bahrain.

- Chronological limitations: The tools of the current research have been applied in the first and second terms in the 2015/2016 academic year.

- Problem limits: The current study subject is limited to the differences between the traditional and the dynamic assessments, according to the theory of the cognitive structures modification using mediated learning with the students with reading disabilities in the fourth grade of primary school in the Kingdom of Bahrain.

\section{Theoretical Framework:}

Traditional assessment depends on an educational philosophy that emphasizes highlighting individual differences and exciting competition among individuals for superior level among his peers without trying to determine the individual 's actual ability, as the narrow look of the traditional assessment that focuses on what the learner stored in his mind of specific information, is no longer suitable for the current and future requirements in this century, Al-Jameel (2014) defines the traditional assessment as a type of assessment that depends on the comparison of the individual's scores with the overall average for others.

Dynamic assessment is that evaluative way in which access to the possible extent of the individual's growth through development that occurs to him or her as a result of the intervention of others who have more knowledge and ability, and they are called examining teachers or mediators who provide mediating experience ranging from tips and encouragement to the explanations and simultaneous questions (Bavali, Yamini \& Sadighi, 2011).

Dynamic assessment is an alternative means of traditional assessment which depends on avoiding the obvious defects of the traditional assessment tools, such as: failure of classification, identification errors, failure at building of educational programs, non availability of equal learning opportunities, also those traditional rating tools help in classification, but they do not supports guidance or training programs, and focus on previous learning (Khedr, 2014).

Dynamic assessment depends on Vygotsky's cultural social theory, that was affected by the research in anatomic, neurological, psychological, social and educational fields. This theory refers to the vital role of social interaction in the growth of individuals and their development process, also it claims that social interaction is the essence of the individuals learning process and knowledge acquiring (Al-Sheikh, 2004).

\section{Research procedures:}

- Research Methodology: The research used the descriptive differentiative methodology, which focuses on identifying the differences between the traditional and the dynamic assessments in the reading disabilities diagnosis. 
Danha Al Hajeri, Nadia Tazi and Mansoor A. Sayyah/The Differences between Traditional and Dynamic Assessment in Diagnosing Students with Reading Disabilities at Primary School in the Kingdom of Bahrain

- $\quad$ Research variables: The research includes two types of variables:

A. Independent variable: The traditional assessment or dynamic assessment.

B. The dependent variable: The number of students diagnosed according to the two assessments (traditional / dynamic) in the word recognition test and reading comprehension test.

- The research sample: the cluster sampling was used for a sample of (504) (69 males and 435 females) from the fourth grade primary school pupils.

- The research tools: The current research used a number of tools, they are divided into two sections:

A. First: diagnosis tools of learning disabilities:

- IQ test: Raven Progressive Matrices Test (Arabized by: Awadh, 1999)

- $\quad$ Learning Disabilities Diagnostic Rating Scale (LDDRS) (El-zayat, 2007).

B. Second: The research data collection tools:

- Word Recognition test (developed by: Al-Fadhil, 2016).

- $\quad$ Reading Comprehension Test (developed by: the researcher).

\section{Research results:}

1. The results of the first question: The number of students with reading disabilities according to traditional assessment is (47) Pupils, and by (97.9\%), while according to the dynamic assessment (39) Pupils, and by (81.3\%). A chi - squared test results show that the difference is statistically significant, with a level of significance value (0.035).

2. The results of the second question: The number of students with word recognition disability according to traditional assessment is (13) pupils, by (27.1\%), while according to the dynamic assessment (4) pupils, by (8.3\%) A chi - squared test results show that the difference is statistically significant, with a level of significance value (0.001).

3. The results of the third question: The number of students with reading comprehension disability according to traditional assessment is (34) Pupils, by (97.1\%), while according to the dynamic assessment (35) Pupils, by (79.5\%).

\section{Research recommendations:}

1. Adoption of dynamic assessment in the diagnosis of learning disabilities as an alternative to the traditional assessment

2. Developing the educational services introduced to LD students on the basis of the Zone of Proximal Development.

3. Developing the educational plans according to the mediated learning experience.

\section{Future research:}

1. An experimental study of the effect of dynamic assessment strategies on the performance of learning disabled and typical children. 
2. A survey Study of the use of dynamic assessment strategies in special education in the Kingdom of Bahrain.

\section{References}

Afif, M., 2014, The purposeful dominant personality pattern and its relationship to achievement motivated: A comparison field study of secondary school students in Mustganm. Platform of Developing Psychological and Educational Practices, 12,151-164.(In Arabic).

Al -Jameel, N., 2014, Building a measure of thought of learning disabled grade 1 primary school pupils. Babylon Center Magazine for Humanistic Studies, 4 (2).410 - 437.(In Arabic).

Al-Fadil, M., 2016,Reading disabilities prevalence rates among primary school students in the Kingdom of Bahrain,Unpublished master thesis, Arabian Gulf University, Bahrain.(In Arabic).

Alharoub, A., 2012, Theoretical issues on the concept of gifted students with learning disabilities. International Journal of Educational Research ,2 (3) 31- 60.(In Arabic).

Al-Melhem, N., 2012,The effect of an enrichment program depending on the dynamic assessment in the development of critical thinking and cognitive beliefs of talented middle school female students, Unpublished master thesis, King Faisal University, Saudi Arabia.(In Arabic).

Al-Sheikh, H. F., 2004,. Comparison between dynamic and Traditional assessment using the (PASS) theory in estimating the performance of an educable mentally retarded sample with impulsive behavior(Cairo: Etrac Publishing and distribution co).(In Arabic).

Awadh, F., 1999,Progressive Matrices Test(Kuwait: Public Authority for Applied Education and Training Press).(In Arabic).

Bavali, M., Yamini, M. and Sadighi, F., 2011, Dynamic assessment in perspective: demarcating dynamic and non- dynamic boundaries. Journal of Language Teaching and Research, 2 (4), 895-902.

El-Zayat, F. M., 2007,Learning Disabilities Diagnostic Rating Scale Manual(Cairo: Publishing House of the universities).(In Arabic).

Khedr, A. B., 2014,The effect of a counseling program based on the dynamic assessment in the development of the slow learners cognitive processes, Unpublished master thesis, Taibah University, Saudi Arabia.(In Arabic).

Rausan, F. (1999). Methods of measurement and diagnosis in special education(Jordan: Dar Alfeqr). (In Arabic).

Salas, N., Gonzalez, F. and Assael, C., 2012, The contribution of dynamic assessment to promote inclusive education and cognitive development of socio-economically deprived children with learning disabilities. Journal of Psychology, 6 (4), 144-168.

Shalabi, A., 2007, The impact of the effectiveness of a remedial teaching program based on the modeled use of Resources room programme to improve the achievement of the learning disabled primary school pupils. A paper presented at the International Conference on School Reform, Al Ain, United Arab Emirates, April.

Swanson, H.L., 1994, The role of working memory and dynamic assessment in the classification of children with learning disabilities. Learning Disabilities Research \& Practice, 9 (4), 190-202.

Swanson, L. and Howard, BH, 2005, Children with reading disabilities: Does dynamic assessment help in the classification. Learning Disabilities Quarterly. 28, 202-223. 